\title{
NOTAS SOBRE ENSINO DE HISTÓRIA E CURRÍCULO: REFLEXÕES SOBRE O CONHECIMENTO HISTÓRICO NO ENSINO FUNDAMENTAL. UBERLÂNDIA-MG. (2000 - 2010)
}

\author{
NOTES ON THE HISTORY TEACHING AND CURRICULUM: \\ REFLECTIONS ON THE HISTORICAL KNOWLEDGE IN THE ELEMENTARY SCHOOL. \\ UBERLÂNDIA-MG (2000-2010)
}

\author{
Regina Ilka Vieira Vasconcelos ${ }^{1}$ \\ Artur Nogueira Santos e Costa ${ }^{2}$
}

\begin{abstract}
RESUMO: Este texto é resultado da pesquisa de Iniciação Científica vinculada ao projeto "Ensino de História e Currículo: experiências com o conhecimento histórico em escolas públicas do ensino fundamental. Uberlândia-MG. (2000 - 2010)", desenvolvido sob os auspícios da Pró-Reitoria de Pesquisa e Pós-Graduação da Universidade Federal de Uberlândia, com financiamento do CNPq. Os principais objetivos concentram-se em compreender e problematizar a organização dos currículos da área de História, no ensino fundamental, em escolas públicas estaduais de Uberlândia-MG, a partir da análise de documentos produzidos, ora nas instâncias do Estado, ora no âmbito das escolas, articulados às experiências de professores e alunos das referidas escolas.
\end{abstract}

PALAVRAS-Chave: História Social e Escola Pública. Ensino de História e Currículo. Conhecimento Histórico. Cotidiano Escolar.

ABSTRACT: This text is result of the Scientific Initiation's research linked to the Project "History Teaching and Curriculum's: experiences with the historical knowledge at public primary schools in Uberlândia-MG. (2000 - 2010)", developed by Research's Pro-Rectory and Pós-Graduate's Studies at the Federal University of Uberlândia, funded by CNPq. The main purposes are understanding and discuss the curriculum's organization in the History area at elementary education in Uberlândia-MG public schools, as from the produced documents analysis, either in State instance or currently in school scope, articulated at the teachers experiences and students of these schools.

KEYWORDS: Social History and Public School. History Teaching and Curriculum. Historical Knowledge. Everyday School.

\footnotetext{
${ }^{1}$ Doutora em História Social pela PUC-SP. Professora dos Cursos de Graduação em História e do Programa de Pós-Graduação em História da UFU.

${ }^{2}$ Graduando em História pela Universidade Federal de Uberlândia. Bolsista de Iniciação Científica do CNPq.
} 
No passado, podiam-se acusar os historiadores de querer conhecer somente as "gestas dos reis". Hoje, é claro, não é mais assim. Cada vez mais se interessam pelo que seus predecessores haviam ocultado, deixado de lado ou simplesmente ignorado. "Quem construiu Tebas das sete portas?" - perguntava

o "leitor operário de Brecht". As fontes não nos contam nada daqueles pedreiros anônimos, mas a pergunta conserva todo o seu peso.

Carlo Ginzburg

Não posso negar-lhe minha postura, mas não posso desconhecer o seu direito de rejeitá-la. Em nome do respeito que devo aos alunos, não tenho por que me omitir, por que ocultar a minha opção política, assumindo uma neutralidade que não existe. Esta, a omissão do professor em nome do respeito ao aluno, talvez seja e melhor maneira e desrespeitá-lo.

o meu papel, ao contrário, é o de quem testemunha o direito de comparar, de escolher, de romper, de decidir e estimular a assunção deste direito por parte dos educandos.

Paulo Freire

\section{Introdução}

O trecho de Carlo Ginzburg inspira pensar sobre temas, sujeitos e abordagens com os quais nos deparamos no cenário historiográfico dos últimos anos e, paralelamente, seus desdobramentos no ensino de história, no âmbito da escola básica. O autor coloca que, a despeito dos antigos historiadores que valorizavam, como objeto histórico, apenas os feitos dos grandes heróis, os novos trabalhos da historiografia têm voltado suas preocupações para aqueles sujeitos que, de algum modo, foram excluídos da cena. Concordando com o autor, no nosso caso, "a pergunta conserva todo o seu peso", e insistimos em recolocá-la(s): será que, no ensino de história, na educação básica, há, de fato, espaço para os sujeitos que antes haviam sido negligenciados? Abandonou-se a pretensão de conhecer as "gestas dos reis"? Os currículos dizem respeito à quais histórias? O ensejo proporcionado pelo trecho de Ginzburg é inquietante, porque nos faz refletir sobre 0 ensino de história que temos acompanhado, cotidianamente. 
Por outro lado, o segundo trecho, de Paulo Freire, conhecido educador brasileiro cujas contribuições acerca das temáticas sobre a escola pública e sobre a educação ainda são inquietantes impele compreender que as escolhas que são feitas, seja na escola, seja no âmbito do currículo, não são neutras. Ao contrário, são resultado de nossas convicções, orientações políticas e objetivos, enquanto cidadãos. Nesse sentido, operar um estudo sobre os currículos é, acentuadamente, perceber que eles são fruto de um recorte, resultado de uma escolha.

Nesse sentido, para introduzir essas notas sobre ensino de história e currículo, consideramos pertinente apresentar a concepção de currículo da qual falamos. Para isso, recorremos às Diretrizes Curriculares Nacionais para o Ensino Fundamental, de 1998, no Parecer 04/98, da Câmara de Educação Básica do Conselho Nacional de Educação, em que assinalam que o principal conceito dessa problemática - o conceito de "currículo" -, contemporaneamente, se desdobra em outros três conceitos. O primeiro é o currículo formal, presente nos planos e nas propostas pedagógicas. Em seguida, observa-se o currículo em ação, composto pelo que se pratica no cotidiano das salas de aula das escolas. E temos, ainda, o currículo oculto, que consiste no que não é tão facilmente visível, mas alimenta aquela prática, por se tratar de um conjunto de referências culturais de professores e estudantes, e contribui para configurar as relações a partir das quais o currículo formal e o currículo em ação ganharão ou não sentido.

Nesse movimento, é possível notar que, no estudo do currículo, a partir dessas três dimensões, nos colocamos diante de um movimento histórico, composto por distintos sujeitos, a saber, alunos, especialistas, professores - com suas relações de tensão, suas experiências e suas inserções sociais - a compor um espaço múltiplo: a escola pública.

Um primeiro apontamento refere-se à escolha pela História Social enquanto fundamentação teórica. Esse campo, em relação ao objeto aqui estudado, nos auxilia a refletir sobre a contribuição dos diferentes sujeitos, com suas múltiplas experiências, que compõem a escola pública e que condicionam a configuração do currículo. Nesse ponto, salientamos a proposição de Déa Ribeiro Fenelon, sobre a relação entre ensino de história e História Social: 
Para o ensino, a História Social ofereceu a possibilidade de substituir perspectivas exclusivamente lineares de uma história contínua e factual, proporcionando ocasião para o surgimento de propostas de estudos temáticos, nem sempre entendidos e aceitos, mas de reconhecida validade, para quantos pretendam desenvolver, em seus alunos, habilidades incontestáveis, quanto à formação do raciocínio e do pensar históricos. Isto permitiria um ensino de História que não fosse apenas uma sucessão de fatos ou animações de temas ou tópicos de programa, que considerasse a perspectiva de que "afinal há uma história tal qual aconteceu" e que precisa ser ensinada, como única capaz de "organizar" o conhecimento histórico, nos níveis de $1^{\circ}$ e $2^{\circ}$ graus. Poderíamos trabalhar de outra maneira, experimentar outras propostas, pois só assim estaremos praticando a nossa disciplina e exercitando nossos compromissos. (FENELON, 1993, p. 76)

Para além de abordar a intersecção entre ensino de história e História Social, a argumentação da autora indica a perspectiva historiográfica que, em nossa concepção, tem muito a contribuir no âmbito do ensino nas escolas públicas. Tal como discutido, não se trata mais de trabalhar com uma história puramente factual e que pretenda dar conta do passado tal como ele aconteceu, mas, outrossim, desenvolver, no aluno, a capacidade de raciocinar historicamente. Nesse sentido, as discussões teóricas nas quais nos apoiamos, no que diz respeito ao currículo e à escola pública, procura ser coerente com essa concepção. Para pensar a escola e as relações de ensino e aprendizagem, tomamos, como ponto de partida, as reflexões de Paulo Freire e, sobre o currículo, o eixo de nossa abordagem se articula aos debates desenvolvidos por Miguel Gonzáles Arroyo. Cabe destacar que, nos dois casos, os autores compreendem a escola de forma democrática e consideram alunos como sujeitos ativos do processo de aprendizagem e, mais, como condicionantes da delineação do currículo.

\section{Primeiros apontamentos...}

Como preâmbulo a essa discussão, retomamos uma reflexão empreendida por Paulo Freire, desde os anos de 1960, cuja validade ainda se faz atual para nosso cotidiano escolar, uma vez que sugere repensar nossas práticas e escolhas, enquanto professores. Em sua obra Pedagogia do Oprimido, escrita no 
Chile, nos anos de 1960, Freire combate uma concepção de educação chamada por ele de "educação bancária". Segundo o autor, nessa perspectiva, o professor, "quanto mais vá 'enchendo' os recipientes com seus 'depósitos', tanto melhor educador será." (FREIRE, 2011, p. 80) E, os alunos, "quanto mais se deixem docilmente 'encher', tanto melhores educandos serão". (FREIRE, 2011, p. 80) E, além disso, na "educação bancária",

o educador escolhe o conteúdo programático; os educandos, jamais ouvidos nesta escolha, se acomodam a ele; [...] Se o educador é o que sabe, se os educandos são os que nada sabem, cabe àquele dar, entregar, levar e transmitir seus saberes aos segundos. Saber que deixa de ser de 'experiência feita' para ser de experiência narrada ou transmitida. (FREIRE, 2011, p. 82-83)

Nesse sentido, a discussão se refere às concepções acerca do processo de ensino-aprendizagem e, implicitamente, aos diferentes posicionamentos políticos a partir dos quais se enxerga a escola. Em linhas gerais, Paulo Freire reforça a necessidade de lutarmos contra essa perspectiva de educação que considera os alunos como passivos, receptáculos de informações, e os professores, de forma autoritária, ditam as regras, transmitem o conhecimento.

No movimento aqui colocado, considerando que o foco de investigação centraliza-se no currículo de história, em sua amplitude, nossa problemática se dirige a algumas questões emaranhadas a esses elementos: na organização dos currículos, com suas distintas dimensões, essa discussão aparece? É possível visualizar, nesse percurso, indícios e iniciativas que valorizem o aluno enquanto sujeito de sua própria aprendizagem? De quem seria essa responsabilidade? No caso da história, que relevância tem esse debate?

\section{Da organização dos currículos e suas implicações}

Miguel Gonzáles Arroyo, em seu livro Currículo, território em disputa, encaminha uma série de importantes reflexões acerca do currículo. Mais do que apresentar respostas, o autor enfatiza a necessária problematização desse campo, a fim de nos inquietarmos e tomá-lo como movimento em aberto. Em certo momento, Arroyo diz: 
As políticas, diretrizes e normas coincidem na priorização de currículos baseados em competências, nas avaliações de resultados, na pressão sobre os docentes, seus compromissos e responsabilidades. [...] Um currículo onde apenas o necessário está previsto, sistematizado, inquestionável, a ser ensinado e aprendido como um ritual-percurso-passagem sagrados para uma economianação fortes será um currículo e uma docência sem liberdade, sem possibilidade de ousadias criativas. (ARROYO, 2011, p. 50-51)

Acompanhando a provocação de Arroyo e, ao mesmo tempo, retomando o debate ensejado por Paulo Freire, como discutido acima, queremos destacar a estreita relação entre a organização dos currículos e os objetivos que se pretende atingir. Práticas pedagógicas, como evidenciado por Arroyo, que se preocupem apenas com a produção de habilidades necessárias para avaliação, e que acabam por tolher a liberdade de criação, carregam consigo ideários e projetos políticos diferentes daquelas cuja valorização, para além dos conteúdos, se centraliza na formação mais ampla do educando, enquanto sujeito social.

Num outro trabalho, também de Arroyo, o autor considera que

[...] o currículo, os conteúdos, seu ordenamento e sequenciação, suas hierarquias e cargas horárias são o núcleo fundante e estruturante do cotidiano das escolas, dos tempos e espaços, das relações entre educadores e educandos, da diversificação que se estabelece entre os professores. (ARROYO, 2007, p. 18)

Considerando a importância conferida ao currículo, como eixo central da organização escolar, é possível estabelecer uma comparação. O que é, para nossos professores, o currículo? Que importância confiam a ele? Para desenvolver esses apontamentos, podemos nos remeter às entrevistas realizadas com professores de diferentes escolas de Uberlândia, sobretudo à questão em que perguntávamos sobre o que eles consideravam como currículo e como se processava a organização do mesmo.

Uma professora que, no ano de 2012, lecionava na Escola Estadual Segismundo Pereira, coloca que "O currículo é os conteúdos que devem ser ministrados naquele determinado ano. A escolha e/ou organização são feitas pelo professor, porém com uma pré-definição do MEC. ${ }^{3 \prime}$ Outra professora, da mesma

\footnotetext{
${ }^{3}$ Entrevista realizada com a professora G. C. M. (que leciona História no Ensino Fundamental, na Escola Estadual Segismundo Pereira, em Uberlândia-MG), no dia 09 de julho de 2012.
} 
escola, acredita que o currículo "é o conteúdo da grade curricular" ". Há, ainda, a fala de um docente da Escola Estadual Rotary, segundo o qual "o currículo corresponde ao conteúdo a ser ensinado e às habilidades que devem ser desenvolvidas pelos alunos. A organização é feita com base no CBC de Minas Gerais ${ }^{5 \prime \prime}$.

É possível desenvolver algumas reflexões a respeito da maneira como os citados professores compreendem o currículo. A primeira refere-se ao fato de que, em todas as falas, o "conteúdo" aparece como sinônimo de currículo, embora o último professor acrescente a dimensão das habilidades. Apesar de termos selecionado apenas três falas, um número destacadamente pequeno diante da quantidade de professores que compõem a rede estadual de Uberlândia, cabe, aqui, ressaltar que tem sido comum, por parte dos professores, essa noção que iguala "conteúdos" e "currículo". Para além de condenar a visão de nossos professores, a questão que analisamos é mais profunda. O que significa tomar o currículo, na área de História, como a pura sequência de conteúdos? Que implicações isso traz para a organização do cotidiano escolar? E, mais do que isso, de que conteúdos se fala?

Talvez, possa trazer implicações preocupantes. Uma delas seria que, ao considerar que o currículo se reduz a isso, nossos professores podem estar abrindo mão de seu direito de participar da gestão escolar, de forma mais ampla, contribuindo para a elaboração dos Projetos Político-Pedagógicos e outros dispositivos. Além disso, ao entender que trata-se apenas da sequência dos conteúdos, podem se ausentar da responsabilidade de eles, enquanto sujeitos ativos no desenho do currículo, operarem escolhas, recortes, definições de conteúdos, e adotarem as propostas oficiais e os livros didáticos como única opção. Na mesma direção, privilegiar simplesmente a lista de conteúdos é colocar de lado o fato de que, mais importante do que os conteúdos, é a lógica sob a qual eles se ordenam, são os objetivos que se pretende atingir com eles, é a relevância que eles expressam, em termos de compreensão de historicidades.

Ainda sobre essa discussão, Arroyo questiona:

\footnotetext{
4 Entrevista realizada com a professora S. A. F. (que leciona História no Ensino Fundamental e Médio, a Escola Estadual Segismundo Pereira) no dia 09 de julho de 2012.

${ }^{5}$ Entrevista realizada com o professor M. T. M. M. (que, em 2012, lecionava História na Escola Estadual Rotary), no dia 05 de julho de 2012. Destaca-se que o CBC corresponde ao Conteúdo Básico Curricular, desenvolvido pela Secretaria de Estado de Educação de MG.
} 
Como o mal-estar nas escolas na relação mestres-alunos pode estar indagando os currículos? As indisciplinas, o desinteresse, teriam a ver com os conteúdos da docência, com os processos de aprendizagem e com a organização escolar e curricular? (ARROYO, 2007, p. 20)

Nesse sentido, a discussão ora pontuada é: há espaço para refletir sobre essas dimensões abordadas por Arroyo, ao considerar o currículo apenas como ordenação de conteúdos? Provavelmente, não. No entanto, por se tratar de tensões que permeiam o cotidiano escolar, elas deveriam compor ordens de discussões que refletissem no currículo, em sua estruturação.

\section{O currículo e os alunos: algumas reflexões}

Novamente acompanhando as indagações de Miguel Arroyo, colocamos a seguinte questão: "[...] os currículos incorporam e trabalham as indagações que os adolescentes e jovens carregam para as salas de aula?" (ARROYO, 2011, p. 223)

Mais do que isso, temos nos perguntado: o que esses alunos têm a nos dizer? E os documentos oficiais, o que dizem sobre eles ou, ainda, propõem para eles? Muitas dessas questões vêm sendo lançadas desde os anos de 1980, a exemplo da conferência pronunciada pela professora Déa Ribeiro Fenelon ${ }^{6}$, em que a mesma se indagava acerca das concepções de ensino, de História, de ciência e de conhecimento sobre as quais se falava, e de como isso se projetava na educação básica. Contudo, tais questões permanecem atuais, porque são sempre desafiadoras, e produzem um deslocamento das certeza ora estabelecidas, no sentido de reavaliar posturas, projetos e objetivos no que concerne ao ensino de história.

Em questionários semi-dirigidos aplicados durante a pesquisa a alunos do ensino fundamental, uma das questões relacionava-se à organização dos conteúdos que compunham os assuntos a serem estudados durante o ano letivo. Perguntávamos: "Você sabe como é feita (e por quem) a seleção de assuntos a

\footnotetext{
${ }^{6}$ Conferência pronunciada no XI Simpósio Nacional de História da ANPUH, João Pessoa, julho de 1981. Cf.: FENELON, D. R. A formação do profissional de História e a realidade do ensino. Tempos Históricos. n. 12, p. 23-35, 2008.
} 
serem estudados ao longo do ano? Comente." $\mathrm{E}$, ainda: "Que assuntos você considera importante estudar em história?" Consideramos pertinente dedicar algumas linhas à análise dos mesmos. ${ }^{7}$

Numa turma de $6^{\circ}$ Ano, da Escola Estadual Leônidas de Castro Serra, 19 alunos responderam ao questionário. Na primeira questão, 14 deles disseram: "não" ou "não sei"; 5 disseram: "o professor". Na segunda questão, as respostas se equilibraram entre: "o presente", "os índios" e "coisas mais interessantes".

Embora pareçam respostas simples e absolutamente pontuais, elas tocam em pontos relevantes. Antes de tudo, estatisticamente falando, é notório que a maioria dos alunos afirma desconhecer o modo como os programas a eles destinados são organizados. Talvez isso seja um indicativo importante acerca do desinteresse do qual se tem reclamado em relação às aulas de História. Talvez, denuncie a falta de diálogo entre os diferentes segmentos que compõem a escola e, consequentemente, a construção de um cotidiano em que as aprendizagens não consigam de fato se efetivarem.

$\mathrm{Na}$ mesma esteira, a segunda questão evidencia um significativo eixo. O que significa reclamar a incorporação de, além dos índios, temas relativos ao presente e, principalmente, mais significativos? Parece-nos que, acompanhando - que se concluiu a respeito da primeira questão, isso indica a falta de articulação entre o que é "relevante" de ser estudado e o que, de fato, se propõe para estudar. Ao mesmo tempo, nos lembramos, nesse caso, de uma reflexão de Miguel Arroyo, em que o autor ponderava a respeito da necessidade de se

[...] trazer as vivências dos educandos [...], e suas experiências sociais, como objeto de pesquisa, de atenção, de análise e de educação. Os conceitos abstratos aparecem distantes das vivências concretas, se tornam estranhos, sem motivação. Logo, criar estratégias para trazer aos processos de aprendizagens as vivências pessoais e as experiências sociais tão instigantes na dinâmica política, cultural, que interrogam seu pensar e seu viver. (ARROYO, 2011, p. 115)

O que Arroyo chama a atenção é que as experiências portadas por todos os alunos, enquanto sujeitos, precisam ser consideradas pelo currículo, e incorporadas a ele. Acreditamos, nesse sentido, que conteúdos "mais

\footnotetext{
7 Ressaltamos que, nas ocasiões em que forem transcritos alguns trechos, os nomes dos alunos não serão mencionados. Indicaremos apenas a série a que os mesmos pertencem.
} 
interessantes", como reclamado pelos alunos, relacionam-se a essa lógica apontada pelo autor. A relevância de um conteúdo, sobretudo em História, se constrói na medida em que o mesmo faça algum sentido para a vida social de quem o estuda ou, como nos ensina E. P. Thompson, que se torne concreto na "experiência" (THOMPSON, 1981). Caso contrário, estaremos apenas estudando fatos do passado, totalmente desconexos da realidade, ou, ainda, "conhecimentos pobres de significados sociais". (ARROYO, 2011, p. 119)

\section{Parâmetros e Conteúdos Curriculares da área de História: o que se pode dizer sobre eles?}

No movimento de elaboração das propostas curriculares da área de História, nas escolas públicas, observa-se que, legalmente, além das Diretrizes Curriculares Nacionais, existem outros dois documentos cujo conteúdo costuma ser levado em consideração. Os Parâmetros Curriculares Nacionais de História (PCN), produzidos em 1998 pelo Ministério da Educação e de abrangência nacional, e os Conteúdos Básicos Curriculares de História (CBC), de 2005, elaborados no seio da Secretaria de Estado de Educação de Minas Gerais, com abrangência estadual. Ambos, com suas especificidades, apresentam propostas curriculares para a área, a partir de justificativas, objetivos, conteúdos, propostas metodológicas e de avaliação. Vamos, aqui, dedicar algumas linhas para discutir alguns pontos sobre eles.

Os PCN, como já dito, foram lançados no ano de 1998, no seio do governo $\mathrm{FHC}^{8}$, como resultado de algumas políticas públicas que se processavam à época. Expressa um modelo de escola, de ensino, de História. Cabe refletirmos sobre isso. Queremos iniciar, aqui, recuperando os pontos principais que o documento traz em sua "Apresentação". Em termos gerais, é colocado que objetivam proporcionar aos educadores a oportunidade de refletir sobre o lugar da História no currículo e na formação dos estudantes. Reconhece que, na área de História, há pluralidade de posicionamentos teóricos e, por isso, deve-se valorizar tanto

\footnotetext{
${ }^{8}$ Sobre a relação dos PCN com o cenário político, é válido conferir o trabalho de Marcos A. da Silva, em que o autor reflete sobre questões de ordem teórico-metodológicas que compõem esse documento e as articulações das mesmas com o avanço neoliberal. Cf.: SILVA, M. A. da. Contra o horror pedagógico. Ensino de história, exclusão social e cidadania cultural. História \& Perspectivas, Uberlândia, v. 1, n. 23, p. 85-98, jul./dez. 2000.
} 
alunos quanto professores que, enquanto sujeitos ativos, têm suas próprias inserções histórico-sociais. Reconhece, ainda, que a realidade escolar brasileira se faz de forma acentuadamente heterogênea, com problemas, características e necessidades que variam de localidade para localidade. Além disso, aponta que

é no dia-a-dia das escolas e das salas de aula, a partir das condições, contradições e recursos inerentes à realidade local e educacional, que são construídos os currículos reais. São grupos de professores e alunos, de pais e educadores, em contextos sociais e educacionais concretos e peculiares, que formulam e colocam em prática as propostas de ensino. Esses parâmetros oferecem mais um instrumento de trabalho para o cotidiano escolar. (BRASIL, 1998, p. 15)

Tais considerações são, a nosso ver, positivas, e contemplam muitos de nossos anseios, contudo, interessa perceber como, no decorrer da construção da proposta, elas se efetivam - se é que se efetivam. Ou seja: quais as reais articulações entre sujeitos concretos, cotidiano escolar, experiências e projeção curricular? Elas avançam para além das páginas dos PCN?

Mais adiante, naquilo que é chamado de "Caracterização da área de História", os PCN retomam o percurso de consolidação da disciplina de História, recuperando os diferentes momentos pelos quais ela passou. Sobretudo no século $\mathrm{XX}$, com os distintos projetos políticos que estiveram em curso, acusam mudanças e transformações na área. Cabe ressaltar o enfoque aos anos 80 pós-ditadura militar - em que se têm marcos importantes, não apenas para a História enquanto disciplina escolar, mas para o campo da História de forma mais ampla. Indica-se, aí, a abertura da ANPUH aos professores de educação básica e o movimento de reformas curriculares nos diferentes estados 9 .

Há que se destacar que, ainda nesse tópico, é possível encontrar referências, sem um grau de profundidade, a correntes historiográficas de matrizes distintas. Algo que é problemático, à medida que é feita a combinação de argumentos histórica e politicamente incompatíveis.

Outro ponto que merece destaque é o fato de que afirmam que

\footnotetext{
9 Sobre esse movimento, conferir o trabalho de Regina Ilka Vieira Vasconcelos: VASCONCELOS, Regina Ilka Vieira. Indagações sobre o lugar da escola pública na produção do conhecimento histórico. In: CARDOSO, H. H. P.; PATRIOTA, R. (Org.). Escritas e narrativas históricas na contemporaneidade. Belo Horizonte: Fino Trato, 2011, p. 31-40.
} 
[...] o saber histórico escolar tem mantido tradições, tem reformulado e inovado conteúdos, abordagens, métodos, materiais didáticos e algumas de suas finalidades educacionais e sociais. [...] nota-se uma crescente preocupação dos professores do ensino fundamental em acompanhar e participar do debate historiográfico, criando aproximações entre o conhecimento histórico e o saber histórico escolar. [...] os profissionais da escola têm procurado manter relações e compromissos mais estreitos com a realidade social, propondo uma melhor compreensão dessa realidade e encarando-a como diversificada, múltipla, conflituosa, complexa e descontínua. (BRASIL, 1998, p. 29-30)

Se, por um lado, nossas propostas e reivindicações para o ensino de história têm se encaminhado na direção desse movimento apontado, por outro, tal afirmação deixa dúvidas quanto à sua projeção no currículo real, na prática. A que exemplos concretos os PCN se referem quando afirmam que há iniciativas de renovação de conteúdos e abordagens? Que materiais didáticos figuram nessas práticas de renovação? Há, de fato, aproximação, diálogo, entre academia e educação básica, como apontado? Essa dicotomia já foi superada? Ou é ainda uma das lutas que se colocam a nós cotidianamente? Qual é essa realidade social a qual, segundo os PCN, os profissionais da escola têm se preocupado em compreender? Essa ordem de questões constitui uma provocação na direção da necessidade de se colocar em xeque, todos os dias, a retórica dos documentos que orientam a organização de nossos currículos. Marcos Silva, nessa esteira, coloca, ainda, mais uma provocação, sobre a qual é válido refletir. Para o autor, os Parâmetros Curriculares Nacionais, da área de História,

[...] internalizam o debate sobre tal campo de conhecimento no mundo dos Grandes Historiadores e das Políticas Oficiais de Ensino, tratando de reduzir os primeiros a algumas fórmulas esvaziadas de ação humana - durações longa, média ou curta (álibi Braudel) e tempo da natureza versus tempo do relógio ou da fábrica (álibi Thompson) - e usando aquelas políticas para ocultar a multiplicidade de interpretações da História que circulam socialmente, além de se equiparem tais Historiadores à ideologia mais rasteira. (SILVA, 2000, p. 90)

Silva, na mesma linha das questões que colocávamos anteriormente, aponta o modo como os PCN se apropriam de autores clássicos da historiografia para a construção de seus argumentos. Para ele, trata-se de uma redução das potencialidades histórico-políticas que compõem as reflexões de Braudel e de Thompson. Além disso, com relação às políticas oficiais, a crítica do autor refere- 
se ao fato de que as mesmas ocultam a heterogeneidade que constitui a rede de educação básica no Brasil e, mais do que isso, pretende tornar invisíveis a rede de contradições em que a escola, a história, os alunos se inserem.

Com relação aos conteúdos para a área de História, com seus critérios de seleção e objetivos, queremos desenvolver algumas considerações. Reconhecendo a multiplicidade de possibilidades de escolha de conteúdos, os PCN adotam, como eixos gerais: "História das representações e das relações de poder" e "História das relações sociais, de cultura e do trabalho". E, nesse sentido, desenvolvem os objetivos referentes a eles colocando que:

\begin{abstract}
Os eixos temáticos e subtemas que deles derivam procuram dar conta de duas grandes questões históricas tão clássicas quanto atuais. A primeira refere-se aos contatos culturais, inter-relações e confrontos entre grupos, classes, povos, culturas e nações. As lutas de culturas e de etnias na defesa de seus territórios e de suas identidades são problemas cruciais do mundo de hoje. São importantes temas de estudo, na medida em que buscam a compreensão da diversidade de modos de vida, de culturas e de representações internas das sociedades e das organizações sociais. São historicamente relevantes por possibilitarem estudos sobre trocas, intercâmbios e confrontos que contribuem para as transformações e as permanências históricas. Favorecem a percepção dos conflitos geradores de situações de dominação, discriminação, luta, igualdade e desigualdade. A segunda questão refere-se às grandes transformações políticas e tecnológicas atuais, que tem modificado as relações de trabalho, as relações internacionais e marcado profundamente o modo de vida das populações. [...] Não se pode negar que este tema de estudo remete para questões atuais e históricas, favorecendo a percepção de transformações na relação dos homens entre si, com a natureza e com as formas de apreensão da realidade e do tempo. (BRASIL, 1998, p. 47-48)
\end{abstract}

Os dois eixos de conteúdos ora comentados, com seus objetivos, parecemnos, de alguma forma, fugir da abordagem tradicional, na medida em que tocam em pontos relativos às camadas populares como ativas na construção de sua história, em que é possível desdobrar questões como: formas de resistência, atuação popular e etc. Aborda, ainda, as relações de trabalho e suas implicações para o cotidiano. Destaca-se, contudo, que os dois eixos desdobram-se de matrizes historiográficas diferentes. Enquanto o primeiro advém da história das representações, das relações de poder, o segundo é resultado da história social, com enfoque no trabalho e na cultura. Embora saibamos que ainda é possível 
problematizar diversos outros pontos relativos aos PCN, queremos, agora, tecer algumas considerações a respeito de outro documento, os Conteúdos Básicos Curriculares - CBC, do Estado de Minas Gerais.

Os CBC, elaborados enquanto Aécio Neves, filiado ao PSDB (partido considerado conservador), era governador do estado de Minas Gerais, são constituídos por um conjunto de reflexões, que perpassam os objetivos de se estudar História, as diretrizes básicas para a construção da proposta, os processos de avaliação e, finalmente, os conteúdos.

Na apresentação, coloca-se que "os CBCs não esgotam todos os conteúdos a serem abordados na escola, mas expressam os aspectos fundamentais de cada disciplina, que não podem deixar de ser ensinados e que o aluno não pode deixar de aprender." (MINAS GERAIS, 2005, p. 9) Aqui, dois destaques se fazem necessários. O primeiro é que reconhecer que a proposta de um documento da espécie dos CBC não representa a totalidade de possibilidades é algo relevante, porque indica que há condição de intervenções por parte do professor. $E$, o outro, refere-se ao fato de que, segundo consta, o que o documento apresenta aspectos que não podem deixar de ser aprendidos. No entanto, perguntamos: que aspectos são esses? Que relevância, de fato, eles possuem? Voltaremos a esse tópico adiante, quando da análise dos conteúdos.

Mais adiante, visualizamos no documento uma série de ponderações de ordem historiográfica, tais como a ruptura com a história tradicional, o enfoque em novas abordagens, em novos sujeitos, a valorização da capacidade de criação do conhecimento por parte dos alunos. Coloca-se, ainda, que a proposta pretende romper com a linearidade e ressaltar a condição de construção sob a qual o conhecimento histórico se sustenta. A exemplo, o trecho seguinte:

O que os historiadores nas novas tendências historiográficas têm em comum é o fato de realizarem vários rompimentos com a história positivista e/ou metódica. Dentre esses se assinalam: a negação da ideia de objetividade e de transparência absoluta dos documentos. Estes, enquanto registros das ações e dos ideais dos homens no tempo, só podem servir como evidências para a construção de explicações históricas se devidamente interrogadas pelo historiador a partir de questões do presente. O conhecimento histórico deixa, assim, de ser mera duplicação do real. O conhecimento histórico, embora ancorado no real e com o objetivo de explicá-lo, torna-se uma construção intelectual resultante do diálogo entre categorias

\section{0}


conceituais - e evidências; entre estas e a visão de mundo ao qual o historiador se filia. Assinala-se, ainda, o abandono da visão linear da história, passando-se a atentar para as relações de mudança e permanência ao longo do tempo, para a existência de múltiplas temporalidades coexistindo num mesmo tempo cronológico; a interdisciplinaridade com as demais ciências sociais, como a antropologia, a sociologia, a geografia, a psicologia, entre outras. Além desses rompimentos, os objetos do conhecimento histórico se deslocaram dos grandes fatos nacionais ou mundiais para a investigação das relações cotidianas, dos grupos excluídos e dos sujeitos sociais construtores da história. (MINAS GERAIS, 2005, p. 14)

O trecho supracitado, retirado dos $\mathrm{CBC}$, apresenta, como dizíamos, uma série de proposta de rompimentos. Cabe, ainda, assinalar o deslocamento da história dos grandes fatos para a perspectiva do cotidiano. Abordando esse movimento de transformação no cenário historiográfico, têm-se a impressão de que o programa de conteúdos presente nos CBC teria essa dimensão, no entanto, não é o que ocorre.

Os conteúdos elencados que, aqui, representam o que os CBC consideram como aspectos "que não podem deixar de ser ensinados", encaminham-se na direção de tópicos que, ora se assemelham à história política tradicional, ora se assemelham a pontos baseados no marxismo estruturalista. Vejamos alguns exemplos:

- Os primeiros europeus: os portugueses do Reino;

- Expansão econômica europeia e descobrimentos marítimos nos séculos XV e XVI;

- O "sistema colonial" e a realidade efetiva da colônia: política metropolitana versus diversificação e interesses locais;

- A agromanufatura do açúcar e a escravidão;

- A economia e a sociedade mineira colonial: dinamismo econômico e diversidade colonial;

- Revoluções liberais: industrial, americana e francesa;

- O Imperador e a Constituição de 1824: fundamentos jurídicos e políticos da monarquia;

- Primeira República: "modernidade", grande propriedade, coronelismo e federalismo;

- A Era Vargas: autoritarismo, estado e nação;

- Neoliberalismo e tensões sociais no Brasil. (MINAS GERAIS, 2005, p. 22-32)

O que se coloca acima são alguns, dos vários exemplos de conteúdos selecionados pelos CBC. É nesse ponto que questionávamos acerca dos aspectos que não podem deixar de ser aprendidos. Questionamos, também: quais 
rupturas esses conteúdos apresentam? Com que linearidade rompem? Pelo que se pode constatar, minimamente intercalam assuntos relacionados à História do Brasil e à História Geral, mas conservam toda a lógica dos preceitos historiográficos com os quais dizem romper.

Tal como apresentam,

a escolha da questão-problema ou eixo norteador da proposta partiu de um problema contemporâneo que pode ser traduzido na pergunta: Quais foram os processos históricos de construção da cidadania e da democracia, considerando as características que essas apresentam hoje na sociedade brasileira? (MINAS GERAIS, 2005, p. 17)

No entanto, a relação entre esse eixo norteador e os conteúdos selecionados para estudos não é visível. Mais do que isso, ficam dúvidas, ainda, quanto à concepção de cidadania da qual se fala. O que é cidadania, na concepção veiculada nos CBC?

Em termos gerais, o documento apresenta, em sua proposta inicial, na introdução, nos objetivos, caminhos relacionados à historiografia renovada, no entanto, não há uma indicação de conteúdos coerentes com esse caminho. Muito pelo contrário, aliás!

\section{Projetos Político-Pedagógicos de escolas estaduais de Uberlândia: o currículo e os desdobramentos para a História}

Aqui, num primeiro momento, rememorar as reflexões de Edward Thompson ${ }^{10}$, sobre a lógica histórica, se faz relevante. O autor, acerca do processo de produção do conhecimento histórico, do trabalho com as fontes, adverte que a lógica de trabalho do historiador precisa se adequar aos fenômenos aos quais dizem respeito, uma vez que os mesmos estão sempre em movimento. Coloca, também, que há uma tênue relação entre as perguntas que se faz aos documentos e o conteúdo da interrogação. Para o autor, é possível

\footnotetext{
10 Ver texto completo: THOMPSON, E. P. Intervalo: a lógica histórica. In: A miséria da teoria ou um planetário de erros: uma crítica ao pensamento de Althusser. Rio de Janeiro: Jahar, 1981 , p. 47-62.
} 
que se coloque qualquer questão às fontes, mas nem todas são adequadas. Ressalta, ainda, que

o conhecimento histórico é, pela sua natureza, provisório e incompleto (mas, não por isso, inverídico); seletivo (mas, não por isso, inverídico, limitado e definido pelas perguntas feitas à evidência (e os conceitos que informam essas perguntas), e, portanto, só 'verdadeiro' dentro do campo assim definido. (THOMPSON, 1981, p. 48-49)

Retomamos a reflexão de Thompson pelo fato de que, não só nesse tópico, mas em todo o trabalho, nossa análise não abarca a totalidade da realidade, nem traz considerações "verdadeiras" e únicas, fechadas. O que se tem é um conjunto de interpretações encaminhadas pelas questões que nos instigam, como já colocado. No caso dos projetos político-pedagógicos e planos anuais de cursos, a que esse eixo se refere, não se realizará uma análise que contemple todas as escolas de Uberlândia, nem se pretende abarcar toda essa realidade. 0 que se propõe, no sentido da lógica histórica, é pontuar algumas evidências acerca do desenho curricular, a partir de suas relações com os documentos aos quais se teve acesso.

O primeiro Projeto Político-Pedagógico analisado é o da Escola Estadual Rotary, referente ao ano de 2003. Após uma breve apresentação do histórico da escola, de seus princípios, objetivos, enveredam no campo do currículo e afirmam que ele

é construído de forma que proporcione aos educandos contato com diferentes elementos da produção cultural humana, incluindo os saberes práticos e produção científica, os produtos de mídia, informática, os filmes, as peças de teatro, as obras literárias, bem como os diferentes artefatos e produção artística das mais diferentes culturas. (PROJETO POLÍTICO-PEDAGÓGICO da Escola Estadual Rotary, 2003, p. 3)

Essas indicações a respeito da lógica a ser seguida para a construção do currículo têm vários pontos que podem ser relacionados ao campo da disciplina de História. A História, por princípio, deve procurar possibilitar a reflexão acerca dos distintos segmentos ali indicados, até porque, todos eles são, para nós, historiadores, fontes documentais e objetos para pesquisa e, com relação aos possíveis desdobramentos, mesmo no sentido dos conteúdos, fornecem a 
possibilidade de se introduzir, no cotidiano da sala de aula, abordagens mais criativas, a partir de novos materiais: cinema, teatro, literatura. E, assim, seria uma possibilidade de encarar a escola como produtora de conhecimento histórico, como sugere Conceição Cabrini (et. all.), em Ensino de História: revisão urgente!

Com relação ao Projeto Político-Pedagógico da Escola Estadual Sérgio de Freitas Pacheco, de 2005, queremos apontar alguns eixos significativos para a discussão aqui empreendida. O primeiro é que, de acordo com o referido documento,

o conhecimento é algo construído e transformado coletivamente. O processo de construção do conhecimento requer muita intencionalidade e deve pautar-se na socialização e na democratização do saber. O conhecimento escolar é dinâmico e não uma simplificação do conhecimento científico, algo estático, acabado, evolutivo e cumulativo. (PROJETO POLÍTICO-PEDAGÓGICO da Escola Estadual Sérgio de Freitas Pacheco, 2005, p. 6)

No trecho acima, é possível apreender vários dos motes sobre os quais discorremos anteriormente. Destacamos a ênfase na concepção de que o conhecimento é construído, tal como dissera Paulo Freire. Mais ainda, exatamente por reconhecer que o conhecimento é construído, reconhece-se, paralelamente, a sua condição de dinamicidade. Não é, pois, mera reprodução do que se produz nos ambientes "científicos", mas movimento, transformação.

Outra ressalva necessária é com relação à organização das turmas. Nesta escola, "a enturmação não é feita com o objetivo de tornar as turmas homogêneas, mas, sim, heterogêneas, onde seja possível a troca de experiências entre os alunos [...]." (PROJETO POLÍTICO-PEDAGÓGICO da Escola Estadual Sérgio de Freitas Pacheco, 2005, p. 14) A relevância dessa consideração se dá na media que, à revelia do que por vezes se tem presenciado, a diversidade de experiências que compõem o universo escolar é o que enriquece a prática educacional. Para o ensino de história, serve de apoio para o debate acerca da pluralidade cultural, da diversidade, enfim, valoriza as discussões contemporâneas de valorização da diferença.

Em relação ao currículo, especificamente, consideram que 
os currículos do ensino fundamental [...] têm uma base nacional comum, complementada por uma parte diversificada, ou seja, pelas características regionais e locais da sociedade, da cultura, da economia e da clientela. (PROJETO POLÍTICO-PEDAGÓGICO da Escola Estadual Sérgio de Freitas Pacheco, 2005, p. 14)

Tal apontamento permite considerar que, no campo da prática, há possibilidade de o professor elaborar propostas que, em consonância com os PCN e $C B C$, contemplem assuntos relacionados às experiências de seus alunos. Ou, como disseram, assuntos "mais interessantes".

Outro Projeto Político-Pedagógico que trazemos para o debate é o da Escola Estadual do Bairro Jardim das Palmeiras, de 2008, no qual colocam que a proposta aqui apresentada busca a

construção da identidade e de organização do trabalho em uma instituição histórica e socialmente situada, constituída por sujeitos culturais que se propõem a desenvolver uma ação educativa, a partir de crenças, desejos, valores e concepções. Visa promover uma educação de qualidade para todos, respeitando diferenças individuais e capacidades de cada aluno, promovendo-o enquanto ser humano capaz e progressivo, sujeito crítico e auto-crítico, responsável por sua formação. (PROJETO POLÍTICO-PEDAGÓGICO da Escola Estadual do Bairro Jardim das Palmeiras, 2008, p. 3)

Valorizamos, aqui, o referencial de que a escola é uma instituição que tem sua inserção histórica e que, por isso, é constituída por sujeitos, que também são históricos. Algo que é também relevante é a consideração de que há diferenças entre cada aluno, diferenças que são de aprendizagem, de compreensão, de entendimento. Não que representem uma hierarquização, mas reafirmam, novamente, a pluralidade histórico-social que se faz presente na escola.

No campo do currículo, consideram que é preciso estabelecê-lo de forma

não-linear, mais flexível, apresentando grande possibilidade de entrelaçamento entre os conteúdos. Na organização, o sentido e o significado de escolarização é a forma do sujeito-cidadão. E a importância dos conteúdos escolares, tradicionalmente considerados, está na sua capacidade de oferecer respostas à vida do aluno. É tarefa do professor procurar estabelecer relações de sentido entre os diferentes conteúdos (disciplinares) e as vivências, considerar saberes e valores do aluno. (PROJETO POLÍTICOPEDAGÓGICO da Escola Estadual do Bairro Jardim das Palmeiras, 2008, p. 3) 
Nesse caso, os enfoques apresentados retomam, de alguma maneira, o debate que direcionamos desde o começo do texto, sobretudo ao enfatizar a necessidade de flexibilidade do currículo, ao passo que o mesmo deve ser pensado a partir do real significado que constituirá para os sujeitos centrais do processo de ensino-aprendizagem: os alunos. Propomos pensar: quais conteúdos, em História, são capazes de contemplar essa dimensão?

A análise dos diferentes Projetos Político-Pedagógicos permite-nos refletir sobre os encaminhamentos que têm sido apresentados acerca da escola pública, do cotidiano escolar, do processo de ensino aprendizagem e, em nosso caso, dos desdobramentos que tais eixos oferecem para a História. Enquanto documentos de pesquisa historiográfica, não apresentam um retrato fiel da realidade, e nem é isso que buscamos, mas, em contrapartida, oferecem elementos que devem ser sempre repensados, a exemplo do que colocamos acima.

\section{Planos Anuais de Curso: o que se propõe para a área de História, no ensino fundamental, em escolas estaduais de Uberlândia?}

Neste tópico, pretendemos discorrer sobre alguns planos anuais de curso da área de História, de escolas públicas estaduais de Uberlândia, relativos ao ensino fundamental. Dos vários planos de curso analisados, fizemos a seleção de quatro, cada um relativo a uma série. Isso se fez porque, apesar das diferenças estruturais, todos eles se assemelhavam muito, em termos de objetivos, propostas e conteúdos. Lembrando mais uma vez da proposição de Thompson, de que é necessário refletir sobre quais perguntas são as mais adequadas a se fazer para as evidências, nossa reflexão se fará a partir da observação de alguns elementos: o que propõem os planos de curso, em termos de objetivos, conteúdos e, ainda, que relação eles têm? É possível perceber a concepção de História na qual eles se fundamental? O que se pode dizer sobre eles?

O primeiro plano anual de curso a que nos deteremos é oriundo da Escola Estadual Conjunto Habitacional Cruzeiro do Sul, elaborado em 2009, para o 60 ano do ensino fundamental. O objetivo nele presente diz respeito à proposta de encaminhar uma prática na qual, não a memorização de fatos, mas a reflexão crítica e interpretação dos vários acontecimentos sejam o foco. Contudo, quando 
se vai analisar os conteúdos propostos para cumprir com esses objetivos, notase uma simples sequência de fatos, colocados em ordem cronológica. Vejamos: As origens do ser humano e sua chegada à América; Egito Antigo; Índia; Grécia: o berço da cultura ocidental; Grécia: do esplendor à conquista macedônica; A formação do Império Romano; O apogeu da civilização romana; A crise de Roma. (PLANO anual de curso, E. E. Conjunto Habitacional Cruzeiro do Sul, 2009, p. 4) A proposta, referente ao estudo da antiguidade, não traz consigo, a priori, as condições de romper com a memorização de fatos e ensejar outra prática de ensino de história. Cabe perguntar que tipo de abordagem foi utilizada pelo professor a fim de cumprir com tal intento, o que não é evidenciado no plano de curso. Com relação à concepção de História, o que se nota é que, aparentemente, os conteúdos parecem estar ligados à concepção tradicionalista, em que figuram apenas fatos "grandiosos".

O segundo plano, relativo ao $7^{\circ}$ ano do ensino fundamental, datado de 2008, pertence à Escola Estadual Professor José Ignácio de Sousa. Indicava que seu objetivo principal concentrava-se em

[...] possibilitar um trabalho mais significativo e transformador, consequentemente, mais realizador na sala de aula, na escola e na sociedade. O plano é o produto deste processo de reflexão e decisão. Não deve ser feito por uma exigência burocrática; ao contrário, deve corresponder a um projeto - compromisso do professor - tendo, pois, suas marcas. A finalidade do plano é criar e organizar o trabalho, Para tanto, deve ser objetivo, verdadeiro, crítico e comprometido. (PLANO anual de curso, E. E. Professor José Ignácio de Sousa, 2010, p. 1)

Aqui, é possível, antes de tudo, destacar a reflexão feita pela professora, de que o plano, para além de um documento formal, representa um norte para o trabalho, e é um recorte operado pelo professor. Há, ao que se parece, uma boa intenção em supor que o mesmo acarretaria em um trabalho significativo e transformador. Mas o que seria um trabalho significativo e transformador? $E$, ainda, os conteúdos para isso propostos expressam esse ideal? Para este nível de ensino, o 70 ano, a escolha de conteúdos contemplava: A Europa Medieval; Árabes, africanos e chineses; Mudanças na Europa; As cruzadas; O declínio do Feudalismo; Mudanças na arte e na religião - o renascimento e a reforma; As grandes navegações; Povos pré-colombianos; O mercantilismo e a colonização 
da América; A administração da América portuguesa. Tais conteúdos, assim como no primeiro plano, são permeados por resquícios da história tradicionalista. Ademais, são absolutamente genéricos e não revelam o que, de fato, se propõe trabalhar. Não queremos, aqui, desmerecer a intenção da professora ao propor um trabalho transformador, contudo, o que se expressa no documento deixa dúvidas quanto à sua força de projeção na prática.

O planejamento anual de História, para o ano de 2010, referente à Escola Estadual Doutor Duarte Ulhoa, para o $8^{\circ}$ ano do ensino fundamental, não apresenta um objetivo geral. Os objetivos específicos são, na verdade, desdobramentos de eixos gerais de conteúdos. Os conteúdos ora apresentados não fogem do que se percebeu em relação aos primeiros planos. Elencam: Iluminismo, Revoluções Americana e Francesa, Conjuração Mineira e Baiana, Era Napoleônica e etc. Contudo, no campo em que expõe sua metodologia, o professor propõe valorizar a relação passado/presente, a interdisciplinaridade e o trabalho com as fontes. Isso pode ser percebido quando o mesmo indica: trabalhar com a Declaração Universal dos Direitos Humanos; Estudar a Confederação do Equador e da personagem histórica de Frei Caneca, a partir da obra Auto do Frade, de João Cabral de Melo Neto. Tais pontos são indícios de opções alternativas de se proceder a discussão dos conteúdos. Embora não indiquem necessariamente um rompimento com a história tradicionalista, merecem destaque por estarem coerentes com a proposta do professor.

Por fim, temos o plano de curso elaborado em 2009, para o 90 Ano, na Escola Estadual do Bairro Jardim das Palmeiras. Ele apresenta apenas os conteúdos propostos para aquela série e o que é chamado de objetivos específicos corresponde aos sub-tópicos dos conteúdos. Os assuntos intercalam história do Brasil e história geral, sem propor qualquer tipo de conexão entre elas. Eis: Brasil - consolidação da República; Primeira Guerra Mundial; Revolução Russa; [...] Segunda Guerra Mundial; Brasil - período getulista. Esses eixos elementares de conteúdos revelam, a exemplo dos outros, a projeção da história tradicional. 


\section{Considerações finais}

Nossa discussão, ancorada na análise dos documentos oficiais relativos ao ensino de história e ao currículo, e na daqueles produzidos no âmbito da escola, não se configura como uma critica, mesmo porque é preciso que reconheçamos as dificuldades pelas quais todos temos passado, no que se refere ao contexto da docência. Contudo, o que nos move é o interesse por compreender a questão do ensino de história, do currículo e da escola pública na defesa desses temas enquanto necessários à formação do historiador.

O debate acerca do currículo e do ensino de história caracteriza-se por contemplar um movimento histórico em processo incessante de transformação. Merece, por isso, ser sempre recolocado. Nenhuma das muitas indagações colocadas por nós, no percurso desse texto, pode ser respondida de forma objetiva. Elas são, contudo, o alimento que move nossa reflexão, e estão ali a nos inquietar sempre que nos deparamos com relatos, assuntos, notícias e ponderações concernentes à temática.

No mais, fica sempre o convite a ocuparmos os espaços de nossa atuação, no sentido de projetar uma escola pública democrática e de qualidade, que abarque um currículo cuja fundamentação seja a de formar sujeitos capazes de se entenderem enquanto históricos e políticos, capazes de intervir em seu presente.

\section{Referências}

AGUIAR, E. P. Currículo e Ensino de História: entre o prescrito e o vivido. Vitória da Conquista - BA, Brasil (1993 - 2000). 199 fl. Dissertação (Mestrado em Educação). Programa de Pós-Graduação em Educação, Universidade Federal de Uberlândia, Uberlândia, 2006.

ARROYO, M. G. Indagações sobre currículo: educandos e educadores: seus direitos e o currículo. Brasília: Ministério da Educação, Secretaria de Educação Básica, 2007.

2011.

. Currículo, território em disputa. 2 ed. Petrópolis, Rio de Janeiro: Vozes,

BENJAMIN, W. Sobre o conceito de história. In: Magia e técnica, arte e política. São Paulo: Brasiliense, p. 222-232. 
BRASIL. Ministério da Educação. Conselho Nacional de Educação. Câmara de Educação Básica. Parecer CEB n.4/98. Diretrizes Curriculares Nacionais para o Ensino Fundamental. Brasília, DF: MEC/SEB, 1998.

BRASIL. Ministério da Educação. Parâmetros Curriculares Nacionais: História. Brasília: Ministério da Educação, Secretaria de Educação Fundamental, 1998.

MINAS GERAIS. Secretaria de Estado de Educação de Minas Gerais. Conteúdo Básico Comum - CBC. Conteúdos Básicos Curriculares de História do Ensino Fundamental. Belo Horizonte: SEE, 2005.

CABRINI, C. et al. $O$ ensino de história: revisão urgente. 4 ed. São Paulo: Brasiliense, 1994.

CRUZ, H. de F.; PEIXOTO, M. do R. C. Discutindo a memória, ensinando a história: uma experiência de educação continuada na PUC-SP. Projeto História. São Paulo, n. 17, p. 415-428, ago. 1998.

Na oficina do historiador: conversas sobre história e imprensa. Projeto História. São Paulo, n. 35, p. 255-272, dez. 2007.

Entrevistas realizadas com professores de Ensino Fundamental (séries finais) em escolas estaduais.

Entrevistas realizadas com alunos de Ensino Fundamental (séries finais) em escolas estaduais.

FENELON, D. R. A formação do historiador e a realidade do ensino. Projeto História, São Paulo, n. 2, p. 7-19, ago. 1982.

. Cultura e História Social: Historiografia e Pesquisa. Projeto História, São Paulo, v. 10, 1994, p. 73-90.

FREIRE, P. Pedagogia do oprimido. 50 ed. Rio de Janeiro: Paz e Terra, 2011. Pedagogia da autonomia. 43 ed. Rio de Janeiro: Paz e Terra, 2011.

GINZBURG, C. O queijo e os vermes: o cotidiano e as ideias de um moleiro perseguido pela Inquisição. Edição de Bolso. São Paulo: Cia das Letras, 2006. GOODSON, I. F. Currículo: teoria e história. Petrópolis: Vozes, 1995.

MOREIRA, A. F. B. (Org.). Currículo: políticas e práticas. Campinas: Papirus, 1999.

MICELI, P. Uma pedagogia da história? In: PINSKY, J. O ensino de história e a criação do fato. São Paulo: Contexto, 2011.

NADAI, E. O ensino de história no Brasil: trajetória e perspectiva. Revista Brasileira de História, São Paulo, v. 13, n. 25/26, p. 143-162, set. 1992/ago. 1993.

PINSKY, J. O ensino de história e a criação do fato. São Paulo: Contexto, 2011.

Projetos político-pedagógicos das escolas estaduais selecionadas durante a pesquisa.

Planos de curso de professores das escolas estaduais selecionadas durante a pesquisa. 
RICCI, C. S. Quando os discursos não se encontram: imaginário do professor de história e Reforma Curricular dos anos 80 em São Paulo. Revista Brasileira de História, São Paulo, v. 18, n. 36, p. 68-88, 1998.

. Da intenção ao gesto: quem é quem no ensino de história em São Paulo. São Paulo: Annablume, 1999.

SILVA, M. A. da. História: o prazer em ensino e pesquisa. São Paulo: Brasiliense, 1995.

Contra o horror pedagógico. Ensino de história, exclusão social e cidadania cultural. História \& Perspectivas, Uberlândia, v. 1, n. 23, p. 85-98, jul./dez. 2000.

SILVA, T. Tadeu da. Documentos de identidade: uma introdução às teorias do currículo. 3 ed. Belo Horizonte: Autêntica, 2011.

THOMPSON, E. P. Intervalo: a lógica histórica. In: A miséria da teoria ou um planetário de erros: uma crítica ao pensamento de Althusser. Rio de Janeiro: Jahar, 1981, p. 47-62.

O termo ausente: Experiência. In: A miséria da teoria ou um planetário de erros: uma crítica ao pensamento de Althusser. Rio de Janeiro: Jahar, p. 180201.

VASCONCELOS, R. I. V. Indagações sobre o lugar da escola pública na produção do conhecimento histórico. In: CARDOSO, H. H. P.; PATRIOTA, R. (Org.). Escritas e narrativas históricas na contemporaneidade. Belo Horizonte: Fino Trato, 2011, p. 31-40.

VIEIRA, M. do P. et al. A pesquisa em história. 5 ed. São Paulo: Ática, 2007.

Recebido em 11 de novembro de 2013. Aprovado em 10 de março de 2014. 